\title{
Relationships of Chamaecyparis formosensis crown shape and parameters with thinning intensity and age
}

\author{
T.M. Yen
}

Yen T.M., 2015. Relationships of Chamaecyparis formosensis crown shape and pa-rameters with thinning intensity and age. Ann. For. Res. 58(2): 323-332.

\begin{abstract}
Taiwan red cypress (Chamaecyparis formosensis Matsum) is an indigenous and important cypress conifer with a broad area of natural forests and plantations in Taiwan. Because of the high economic value and multiple uses of the species, numerous researchers have studied its growth and yield within plantation forests. However, few studies have examined how the crown characteristics of the tree respond to different thinning regimes, particularly in the long run. The crown is a dominant outline of aboveground component of a tree that can sensitively reflect competitions from trees located nearby. This study evaluated the crown form of Taiwan red cypress at three different growth stages with different thinning intensities over 20 years. The study began in 1982, when the three plantations examined were aged 7, 15, and 21 years, and when thinning treatments began. In 2002, crown form parameters (CFPs) and crown profile equations (CPEs) were used to analyze the thinning effects at the tree level. Two-way analysis of variance (ANOVA) revealed that age class influenced most CFPs and that thinning treatments influenced all CFPs, indicating that both factors could simultaneously affect the CFPs. Moreover, the CPEs fit the observed data well for all age classes, demonstrating that the equation had a high capacity for predicting crown form. The CPEs were used to determine the mean crown shape profile for each thinning treatment and age class. According to the mean crown profile predicted by CPEs, we found that crown length and width increased with thinning intensity for all aged trees, especially after a heavy thinning treatment. Keywords thinning effect, thinning trial, crown form parameter, crown profile equation.
\end{abstract}

Authors. Tian-Ming Yen (tmyen9999@gmail.com) - Department of Forestry, National Chung-Hsing University; Address: No. 250, Kuo Kuang Road, South District, Taichung, 40227, Taiwan.

Manuscript received February 02, 2015; revised June 22, 2015; accepted June 29, 2015; online first June 29, 2015.

\section{Introduction}

Approximately 2.1 million ha of forestland exist throughout Taiwan, covering $58.5 \%$ of the total land area and exhibiting high biodiversity. (Taiwan Forestry Bureau (TFB) 1995, 
Yen et al. 2013, Yen \& Wang 2013, Yen 2015). Among these forest resources, plantation forest is critical, comprising approximately 420,000 ha (TFB 1995). The management targets of most plantation forests involve timber production and, increasingly in recent years, carbon storage (Yen \& Wang 2013). Taiwan red cypress (Chamaecyparis formosensis) is an indigenous cypress and an ideal representation of conifers in Taiwan, which possess ecological and economic value (Liu et al. 1988, Yen et al. 2009, 2013). Native natural forests of Taiwan red cypress grow at an elevation between 1,500 and 2,300 $\mathrm{m}$ (Liu et al. 1988). The same cypress was also widely planted at this elevation after natural forests were heavily logged (Lee 1985, Liu et al. 1988, Yen et al. 2009, 2013). Consequently, a large area of plantation forest of Taiwan red cypress exists. In general, Taiwan red cypress and Taiwan hinoki cypress (Chamaecyparis obtusa) are usually categorized as a single cypress forest, namely, a Taiwan cypress forest, which occupies approximately 24,800 ha of man-made forest in Taiwan (TFB 1995, Yen et al. 2013).

Because Taiwan red cypress possesses excellent physical properties appropriate for multiple uses, numerous studies have developed growth and yield models to analyze the thinning of this cypress (e.g., Yen 1999, Yen et al. 2009, 2013, Li \& Yen 2010). The results have revealed that reasonable thinning can enhance the growth rate of Taiwan red cypress at tree and stand levels. However, little research has been done on the long-term effects of thinning on the crown characteristics of Taiwan red cypress. Yen et al. (2013) examined how Taiwan red cypress aboveground biomass allocation patterns and vertical distribution of crown parameters were influenced 20 years after thinning. The results indicated that these two crown characteristics were altered according to thinning intensity and suggested that the influence of thinning on different tree aspects should be further examined, particularly regarding the influence on the crown shape.
The crown is the dominant aboveground component of woody plants and can effectively reflect growth stages, competition with other plants, and environmental stresses. Therefore, the crown condition is widely used to analyze how competition and environmental stresses influence tree development (Kramer \& Kozlowski 1979, Baldwin \& Peterson 1997, Yen et al. 2006, 2013). Crown property changes according to stand density, thinning treatment, and site conditions have widely been reported in plantation forests (Brix 1981, Baldwin \& Peterson 1997, Baldwin et al. 2000, Pinkard \& Neilsen 2003, Yu et al. 2003, Filipiak 2005, Wang et al. 2013). Because tree development is closely correlated with crown condition, crown properties are usually used to predict tree growth and evaluate tree health in plantation forests. Crown properties can be quantified under different conditions by using crown form parameter (CFP) and crown profile equation (CPE) (Baldwin et al. 2000, Yen et al. 2006, Chen et al. 2010). Any crown characteristic (e.g., crown width, crown area, crown volume and crown biomass) can be taken as CFP, whereas CPE predicts the crown outline at various heights based on special equations. CFP and CPE have been used to evaluate crown changes in relation to thinning and can accurately exhibit crown conditions resulting from thinning (Baldwin et al. 2000).

This study examined the CFP and CPE of Taiwan red cypress 20 years after thinning and evaluated the effects of a long-term thinning trial on crown properties at different growth stages. The objectives were to analyze CFP and CPE to determine how thinning affected crown characteristics in different growth stages.

\section{Materials and methods}

\section{Study plantation}

The study area was located in Central Taiwan $\left(24^{\circ} \mathrm{N}, 121^{\circ} \mathrm{E}\right)$, in national forests administered 
by the Taiwan Forestry Bureau (TFB). Native natural forests of Taiwan red cypress were widely distributed in this area in the past (Yen et al. 2013). Much of these natural forests had been logged, with this activity particularly frequent from 1960 to 1980 (Lee 1985, Yen 2002, Yen et al. 2013). The same tree species was also planted in this region after the logging of natural forests. Consequently, a large area of plantation forest of Taiwan red cypress exists in this area and much research into its growth and yield field has been conducted (e.g., Yen et al. 2009, 2013; Li \& Yen 2010). Our study also examined site conditions in these plantation forests, specifically within three plantations planted in 1961, 1967, and 1975 covering $18.69,16.42$, and 22.53 ha, respectively (Lee 1985, Yen et al. 2013). Initial spacing of $1.75 \times 1.75 \mathrm{~m}\left(3,265\right.$ stems $\left.^{-1}\right)$ was adopted for planting in each of these stands (Lee 1985). The thinning trial began simultaneously in 1982, when the three plantations were 7, 15, and 21 years old (Lee 1985). These three stands had similar sites, confirmed by similar site index curves based on determined tree height (Lee \& Yen 2000). The basal area (BA) of the stands was used as the main criterion for thinning operations, and thinning was done from below (removing suppressed trees) to improve the development of overstory trees (dominant trees) (Yen et al. 2013). Four treatment levels were performed for each of the three age classes, namely heavy thinning (thinning 45\% BA), medium thinning (thinning 30\% BA); light thinning (thinning 15\% BA); and no thinning. Each thinning level had three replicates, each of which covered 0.05 ha $(20 \times 25 \mathrm{~m})$. Each age stand covered 0.6 ha, resulting in a total trial area of 1.8 ha (Lee 1985, Yen et al. 2013). This study conducted a thinning trial in 1982 and assessed its long-term effects, particularly on crown characteristics. Previous studies have examined stand characteristics before and after the thinning and indicated that tree number and BA decreased with thinning intensity in each age stand after thinning; higher BAs and fewer trees were observed in older stands before thinning (Lee 1985, Yen et al. 2013). For detailed stand characteristics before and after thinning, please refer to Lee (1985) and Yen et al. (2013). The soil type of the study sites was a humic brown soil, which is appropriate for Taiwan red cypress growth (Lee 1985). According to the 1980-2010 records from the Sun Moon Lake weather station, the monthly temperature ranged from 14.2 to $23.0^{\circ} \mathrm{C}$, and annual rainfall was $2401.9 \mathrm{~mm}$ per year (Taiwan Central Weather Bureau 2013).

\section{Sampling trees}

This study investigated the thinning effects on crown properties by analyzing sample trees from different thinning treatment groups. To understand the effect on crown and tree properties 20 years after thinning, one representative tree per plot, determined according to the mean diameter at breast height $(\mathrm{DBH})$ of each plot, was selected as a sample (Yen et al. 2013). A total of 36 sample trees was measured after being felled in October 2002. All trees were felled at a height of $0.3 \mathrm{~m}$ above the soil surface. The tree height $(\mathrm{H})$ and whole crown characteristics (e.g. crown length, crown width) of each sample tree were measured and then divided into $1 \mathrm{~m}$ sections to measure their crown diameter and other properties. A previous study (Yen et al. 2013) examined the aboveground biomass allocation following thinning, our study mainly focuses on crown characteristics. Essential CFPs, such as crown length (CL), living clear length (LCL), and maximum crown width (MCW), are summarized in Figure 1.

Other CFPs were conducted from these essential CFPs, including the live crown ratio (LCR), live clear length ratio (LCLR), and crown length to crown width ratio (CLWR), with: $\mathrm{LCR}=\mathrm{CL} / \mathrm{H}, \mathrm{LCLR}=\mathrm{LCL} / \mathrm{H}$, and $\mathrm{CLWR}=\mathrm{CL} / \mathrm{MCW}$. 
(a) Crown parameter

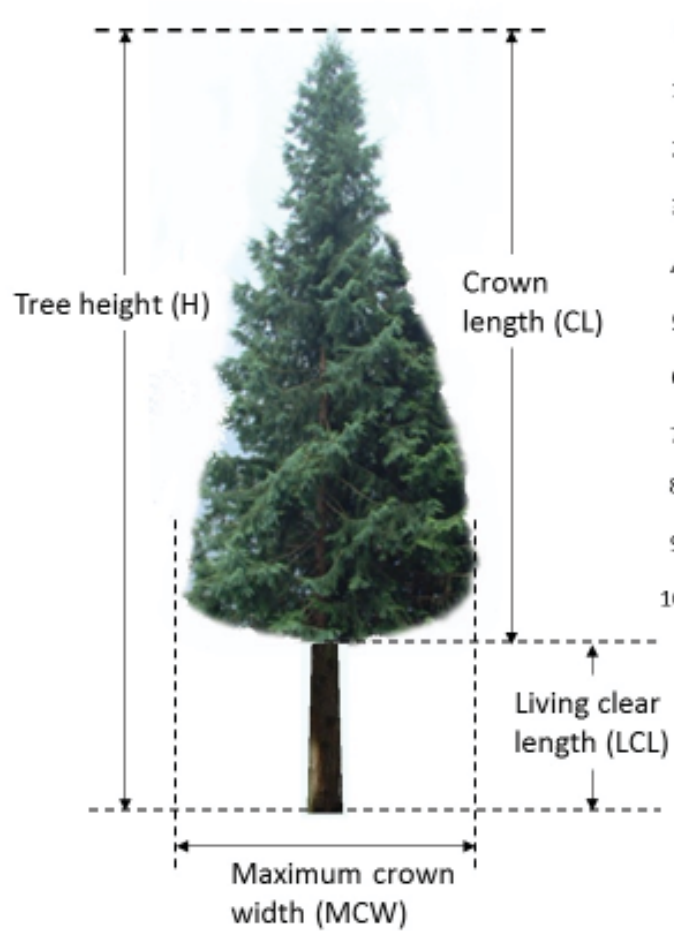

(b) Crown shape (profile)

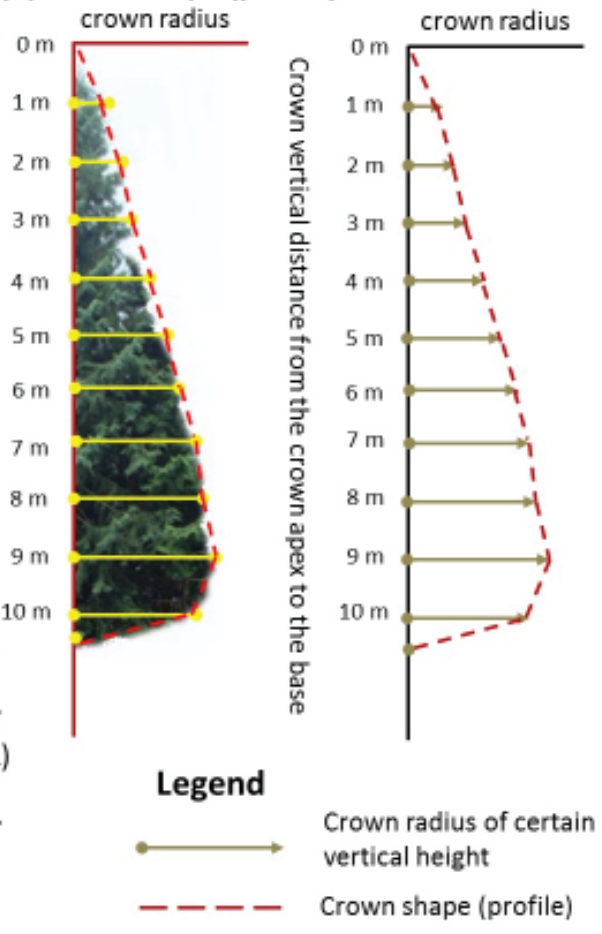

Figure 1 An illustration of essential crown from parameter at tree level (the image was taken by author and was modified by image software)

\section{Data analysis}

The abovementioned CFPs were measured for each sample tree. Because this study examined the effects of thinning on the crown properties of trees of various ages, thinning intensity and tree age were main variables. A two-way analysis of variance (ANOVA) was designed to examine the CFPs; the age factor comprised three levels $(27,35$, and 41 years $)$ and the thinning factor comprised four intensities (heavy, medium, light, and no thinning). The least significant difference (LSD) method was used to compare treatment means when the ANOVA results were significant $(P<0.05)$.

Multiple regression analysis was conducted to predict crown profiles by using the model proposed by Baldwin \& Peterson (1997), with the following CPE (Equation 1). ratio, $\mathrm{RCH}$ - crown radius calculated at a relative crown height, and a, b, c, d, e, f are the regression coefficients.

The data used in this model was calculated at different crown radii with a relative crown height, and the source of this data was derived from detailed measurements of $1 \mathrm{~m}$ sections of each sample tree (see Figure 1). DBH and LCR are the main dependent variables of this model, where LCR is the live crown ratio, the same as the LCR in the CFPs. The parameters of this multiple regression model were predicted using a stepwise method, and three different aged trees were predicted separately.

\section{Results}

The CFPs were obtained from sample trees with different thinning treatments in each age class and where CR - crown radius, LCR - live crown were tested using two-way ANOVA. Table 1 
summarizes the $F$-value and $P$-value results.

The two-way ANOVA revealed that all CFPs except CLWR $(P=0.4736)$ were influenced by age class; all CFPs were influenced by thinning treatment (Table 1), indicating that both factors simultaneously affected the CFPs. To understand the influence of these two factors on the CFPs, this study analyzed the relationship between the CFPs and age class, as shown in Figure 2. The CFPs with age classes can be divided into three categories, i.e., those that increased with age (CL, LCL, MCW, and LCR), decreased with age (LCLR), or were unrelated to age (CLWR).

The CFPs and thinning treatments were analyzed in each age class to determine their relationships. One-way ANOVA and LSD analysis were used to examine the CFPs among different thinning treatments, as shown in Table 2.

Table 2 reveals that LCL decreased with thinning intensity, whereas $\mathrm{MCW}$ increased with thinning intensity, regardless of age. The other CFPs varied according to age. Notably, more CFPs were influenced by thinning intensity in 27-year-old trees (CL, LCL, MCW, LCR and LCLR) than in 41-year-old trees (LCL, MCW, and CLWR). In the 27-year-old trees, $\mathrm{CL}$ increased with thinning intensity and varied significantly between thinning treatments, whereas the effects of thinning on CL were not obvious in the other age classes. In the 27and 35-year-old trees, the LCR increased and the LCLR decreased with thinning intensity; however, these trends were not observed in the 41-year-old trees. The CLWR only varied significantly between thinning treatments in the 41-year-old trees; a higher CLWR (2.26) was recorded for the no-thinning treatment, revealing a significant difference to the thinning treatments (1.81-1.89).

The data set of each age class included four thinning treatments, and three regression functions were obtained for each age class (Table $3)$. The CPE fit the observed data well for all age classes (each with a high $R^{2}$ ), revealing that this model had a high capacity for predicting crown form. Some regression coefficients (e.g., the c coefficient in 27- and 35-year-old trees and the e coefficient in 41-year-old trees) do not appear in Table 3; this is because the stepwise regression method was used to solve the regression coefficients and some coefficients do not enter into the regression models. However, the CPE of this study adopted relative scales; therefore, when determining the mean profile of the crown shape, the CL of trees with different thinning treatments in each age class should be considered. The mean crown shape profile for the thinning treatments is illustrated in Figure 3 for each age class.

The mean profile of the crown shape revealed more detailed information concerning how thinning affects crown development. We found that crown width increased with thinning intensity, regardless of age. This result implies that thinning, particularly heavy thinning, increases crown body size.

Table 1 Summary of the two-way ANOVA testing crown form parameters

\begin{tabular}{lllll}
\hline \multirow{2}{*}{ Crown parameter } & \multicolumn{4}{l}{ Factor } \\
\cline { 2 - 4 } & Age category & Thinning & \\
\cline { 2 - 4 } & F-value & 0.0000 & F-value & P-value \\
\hline CL $(\mathrm{m})$ & 44.14 & 0.0101 & 5.67 & 0.0034 \\
LCL $(\mathrm{m})$ & 5.38 & 0.0000 & 33.55 & 0.0000 \\
MCW (m) & 62.09 & 0.0005 & 23.59 & 0.0000 \\
LCR & 9.94 & 0.0005 & 22.68 & 0.0000 \\
LCLR & 9.94 & 0.4736 & 22.68 & 0.0000 \\
CLWR & 0.77 & 5.31 & 0.0047 \\
\hline
\end{tabular}

Note. Abbreviations: CL - crown length, LCL - living clear length, MCW - maximum crown width, LCR - live crown ratio, LCLR - live clear length ratio, CLWR - crown length to crown width ratio. 


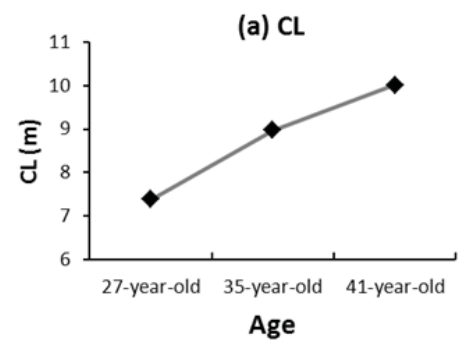

(c) MCW

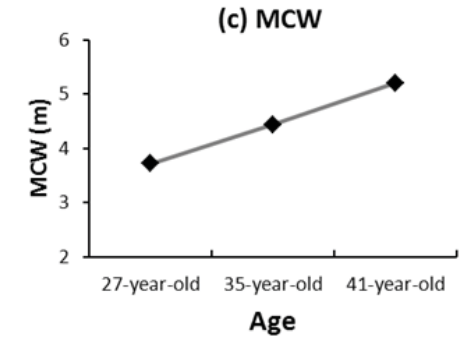

(e) LCLR

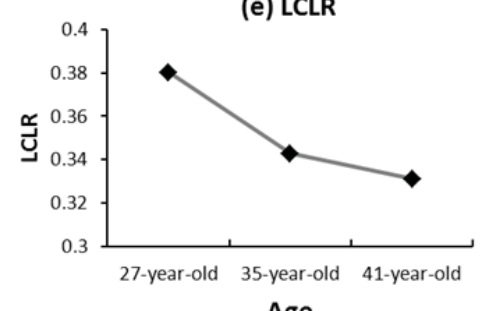

Age

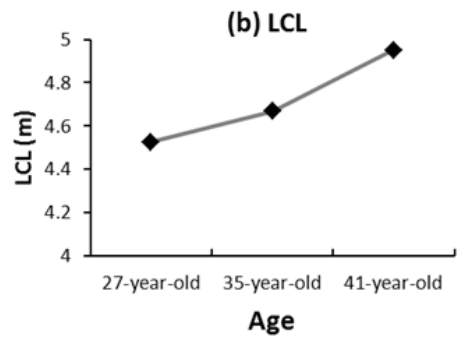

(d) LCR

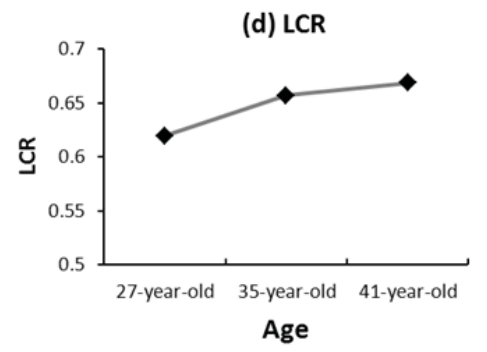

(f) CLWR

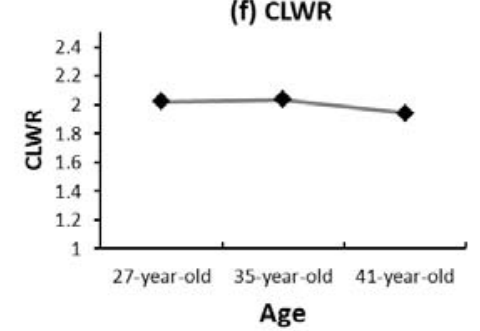

Figure 2 Trends of crown form parameters of different aged trees (CL - crown length, LCL - living clear length, MCW - maximum crown width, LCR - live crown ratio, LCLR - live clear length ratio, CLWR - crown length to crown width ratio)

\section{Discussion}

This study investigated how thinning affects crown form at tree level by examining three even-aged Taiwan red cypress plantations 20 years after thinning. Numerous aspects of thinning, such as its effect on crown properties, individual tree growth, and stand stocking, has been studied in coniferous stands worldwide (Ginn et al. 1991, Baldwin et al. 2000, Yen 2002, Yu et al. 2003, Mäkinen \& Isomäki 2004, Simard et al. 2004, Li \& Yen 2010). Such studies have revealed that thinning improves the stand volume growth rate, tree growth, and crown development of the remaining trees. However, thinning also affects the remaining trees in dimensions that may vary according to the length of periods after thinning (short term or long term), thinning intensity, and environmental conditions. The Taiwan red cypress is an economically valuable tree species; therefore, numerous thinning studies have examined the growth and yield of the species (e.g., Hwang 1977, Yen et al. 2009, 2013, Chen et al. 2010, Li \& Yen 2010). Previous studies have demonstrated a relationship of thinning with growth and yield. We also found an interesting issue on assessing the contribution of carbon storage and sequestration to thinning for Taiwan red cypress forests (Yen \& Wang 2013). The results demonstrated that thinning improved growth rate at the stand level, implying that thinning positively contributed to carbon sequestration. However, the effects of long-term thinning on the crown characteristics of this species at different growth stages have rarely 
Table 2 Treatment means of crown form parameters of 27-, 35- and 41-year-old Taiwan red cypress, respectively

\begin{tabular}{lrlllll}
\hline \multirow{2}{*}{ Age $\begin{array}{l}\text { Crown form } \\
\text { parameter }\end{array}$} & ANOvalue & P-value $\begin{array}{l}\text { Heavy } \\
\text { thinning }\end{array}$ & $\begin{array}{l}\text { Medium } \\
\text { thinning }\end{array}$ & Light thinning & No thinning \\
\hline 27 years CL (m) & 8.10 & 0.008 & $8.40 \pm 0.62^{\mathrm{b}}$ & $7.37 \pm 0.51^{\mathrm{a}}$ & $6.93 \pm 0.31^{\mathrm{a}}$ & $6.83 \pm 0.12^{\mathrm{a}}$ \\
LCL (m) & 13.79 & 0.002 & $3.57 \pm 0.31^{\mathrm{a}}$ & $4.53 \pm 0.32^{\mathrm{b}}$ & $4.83 \pm 0.35^{\mathrm{b}}$ & $5.17 \pm 0.31^{\mathrm{b}}$ \\
MCW (m) & 5.75 & 0.002 & $4.43 \pm 0.47^{\mathrm{c}}$ & $3.97 \pm 0.47^{\mathrm{bc}}$ & $3.37 \pm 0.42^{\mathrm{ab}}$ & $3.10 \pm 0.36^{\mathrm{a}}$ \\
LCR & 16.71 & 0.001 & $0.70 \pm 0.03^{\mathrm{c}}$ & $0.62 \pm 0.02^{\mathrm{b}}$ & $0.59 \pm 0.02^{\mathrm{ab}}$ & $0.57 \pm 0.02^{\mathrm{a}}$ \\
LCLR & 17.50 & 0.001 & $0.30 \pm 0.03^{\mathrm{a}}$ & $0.38 \pm 0.02^{\mathrm{b}}$ & $0.41 \pm 0.02^{\mathrm{bc}}$ & $0.43 \pm 0.02^{\mathrm{c}}$ \\
CLWR & 1.41 & 0.309 & $1.92 \pm 0.34^{\mathrm{a}}$ & $1.87 \pm 0.12^{\mathrm{a}}$ & $2.07 \pm 0.19^{\mathrm{a}}$ & $2.22 \pm 0.23^{\mathrm{a}}$ \\
\hline 35 years CL (m) & 1.85 & 0.217 & $9.93 \pm 1.12^{\mathrm{a}}$ & $8.87 \pm 0.65^{\mathrm{a}}$ & $8.80 \pm 1.01^{\mathrm{a}}$ & $8.30 \pm 0.61^{\mathrm{a}}$ \\
LCL (m) & 22.68 & 0.000 & $3.83 \pm 0.31^{\mathrm{a}}$ & $4.37 \pm 0.25^{\mathrm{ab}}$ & $4.93 \pm 0.15^{\mathrm{bc}}$ & $5.53 \pm 0.32^{\mathrm{c}}$ \\
MCW (m) & 8.34 & 0.008 & $4.90 \pm 0.26^{\mathrm{b}}$ & $4.63 \pm 0.25^{\mathrm{b}}$ & $4.40 \pm 0.26^{\mathrm{ab}}$ & $3.80 \pm 0.31^{\mathrm{a}}$ \\
LCR & 11.51 & 0.003 & $0.72 \pm 0.04^{\mathrm{c}}$ & $0.67 \pm 0.03^{\mathrm{b}}$ & $0.64 \pm 0.02^{\mathrm{b}}$ & $0.60 \pm 0.00^{\mathrm{a}}$ \\
LCLR & 11.29 & 0.003 & $0.28 \pm 0.04^{\mathrm{a}}$ & $0.33 \pm 0.03^{\mathrm{b}}$ & $0.36 \pm 0.02^{\mathrm{bc}}$ & $0.40 \pm 0.00^{\mathrm{c}}$ \\
CLWR & 0.53 & 0.672 & $2.03 \pm 0.27^{\mathrm{a}}$ & $1.92 \pm 0.21^{\mathrm{a}}$ & $2.01 \pm 0.33^{\mathrm{a}}$ & $2.17 \pm 0.13^{\mathrm{a}}$ \\
\hline 41 years CL (m) & 0.43 & 0.740 & $10.43 \pm 0.35^{\mathrm{a}}$ & $9.80 \pm 0.36^{\mathrm{a}}$ & $9.80 \pm 1.28^{\mathrm{a}}$ & $10.0 \pm 0.79^{\mathrm{a}}$ \\
LCL (m) & 5.41 & 0.025 & $4.37 \pm 0.38^{\mathrm{a}}$ & $4.73 \pm 0.31^{\mathrm{ab}}$ & $5.33 \pm 0.38^{\mathrm{b}}$ & $5.37 \pm 0.38^{\mathrm{b}}$ \\
MCW (m) & 10.14 & 0.004 & $5.77 \pm 0.31^{\mathrm{b}}$ & $5.43 \pm 0.35^{\mathrm{b}}$ & $5.20 \pm 0.40^{\mathrm{b}}$ & $4.43 \pm 0.06^{\mathrm{a}}$ \\
LCR & 2.14 & 0.174 & $0.71 \pm 0.01^{\mathrm{a}}$ & $0.67 \pm 0.02^{\mathrm{a}}$ & $0.65 \pm 0.04^{\mathrm{a}}$ & $0.65 \pm 0.03^{\mathrm{a}}$ \\
LCLR & 2.14 & 0.174 & $0.29 \pm 0.01^{\mathrm{a}}$ & $0.33 \pm 0.02^{\mathrm{a}}$ & $0.35 \pm 0.04^{\mathrm{a}}$ & $0.35 \pm 0.03^{\mathrm{a}}$ \\
CLWR & 6.25 & 0.017 & $1.81 \pm 0.04^{\mathrm{a}}$ & $1.81 \pm 0.18^{\mathrm{a}}$ & $1.88 \pm 0.10^{\mathrm{a}}$ & $2.26 \pm 0.21^{\mathrm{b}}$ \\
\hline
\end{tabular}

Note. Abbreviations: CL - crown length, LCL - living clear length, MCW - maximum crown width, LCR - live crown ratio, LCLR - live clear length ratio, CLWR - crown length to crown width ratio, and the one-way ANOVA and LSD method were used to test the crown form parameters among different thinning treatments The treatment means (mean \pm standard deviation) marked with the same letter are not significantly different at $p=0.05$ by the LSD method (in the same line).

Table 3 Summary of the multiple regression models in each age category

\begin{tabular}{|c|c|c|c|c|c|c|c|c|c|}
\hline \multirow{2}{*}{ Stand age } & \multicolumn{6}{|c|}{ Regression coefficient } & \multirow{2}{*}{-F-value } & \multirow{2}{*}{ P-value } & \multirow{2}{*}{$R^{2}$} \\
\hline & $\mathrm{a}$ & $\mathrm{b}$ & $\mathrm{c}$ & $\mathrm{d}$ & $\mathrm{e}$ & $\mathrm{f}$ & & & \\
\hline 27 years & -6.20 & 0.63 & - & 4.45 & -0.61 & -0.60 & 1528.1 & 0.000 & 0.99 \\
\hline 35 years & 3.48 & 0.20 & - & -3.72 & -0.24 & 0.49 & 1097.3 & 0.000 & 0.98 \\
\hline 41 years & -0.11 & -0.35 & 19.77 & 0.83 & - & -13.45 & 1388.4 & 0.000 & 0.99 \\
\hline
\end{tabular}

Note. a symbol of '-' is regression coefficients not entered in the regression models for each stand

been addressed. Expanding knowledge in this area aids in understanding the mechanisms between crown development and tree growth.

Crown form is influenced by various factors, such as the growth stage, environmental conditions, and silvicultural method, as reported in previous studies (Hashimoto 1991, Baldwin et al. 2000, Cai et al. 2013). Because crown prop- erties change with various factors, this study examined specifically the thinning factor and stand age in Taiwan red cypress plantations. Because the three differently aged stands were located at similar sites (Lee \&Yen 2001), stand density was a key factor affecting tree and stand developments, and the effects of thinning on crown characteristics were determined for 
(a) 21-year-old

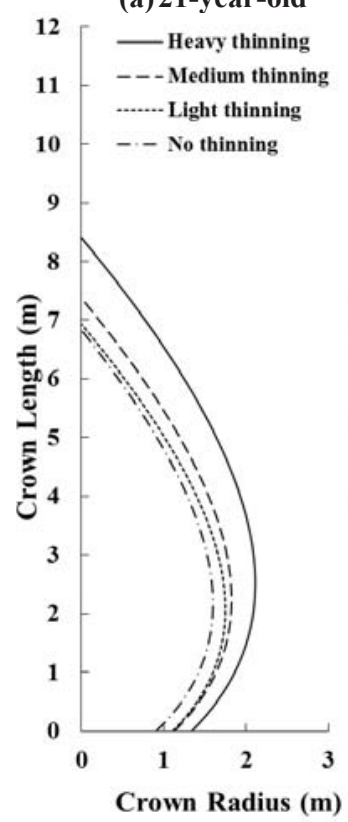

(b)35-year-old

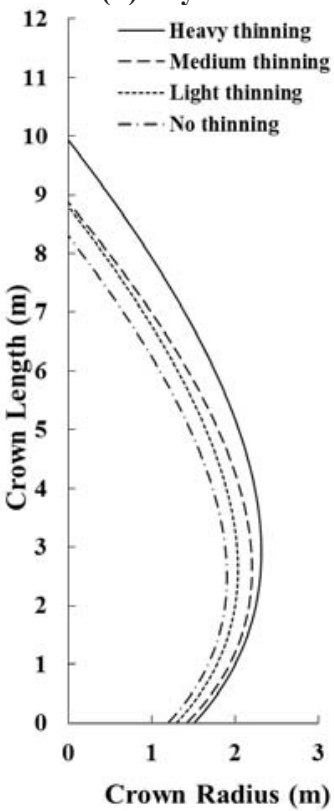

(c) 41-year-old

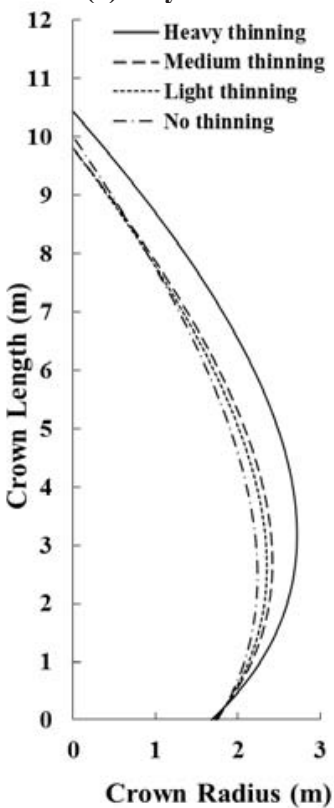

Figure 3 Mean profile of the crown shape after thinning treatments in different age classes

three ages, 20 years thinning. Numerous studies have reported that tree growth accompanies changes in crown form and structure, whereas crown properties are influenced by thinning (Hashimoto 1991, Baldwin et al. 2000). Although the CPE is a simple means of assessing crown development, it can determine certain crown conditions resulting from growth stages and environmental factors (Yen et al. 2006, Chen et al. 2010). The two main factors of age and thinning were used to evaluate the CPEs. Because the study plantations were even-aged, the crown properties appeared homogenous at tree level. The crown characteristics of the sample trees can reflect the thinning levels of each stand. Our results showed that CL, LCL, $\mathrm{MCW}$, and the LCR increased with age, whereas the LCLR decreased with age (Fig. 2).

In general, CL, LCL, and MCW increasing with age could be expected during tree growth. The LCR, which reflected the ratio of CL to $\mathrm{H}$, increased with age in the Taiwan red cypress (Fig. 2). The CLWR indicates the ratio of crown length to crown width; however, the CLWR did not exhibit a significant difference among age classes and was close to 2 in every age class. This study also found that the effects of thinning may not be consistent across all age classes of the Taiwan red cypress. We found only that MCW increased and the LCL decreased with thinning intensity, regardless of age.

This research adopted the CPE, using DBH, $\mathrm{LCR}$, and $\mathrm{RCH}$ as variables to predict the crown ratio at each relative crown height, as proposed by Baldwin \& Peterson (1997). Tree age was also found to be a predictor variable that adds to the original model (Baldwin \& Peterson 1997). Because our study comprised only three age classes, the CPE was separately predicted for each age class. For this reason, the age variable was not included in the model in this study. Because of a closely predicted result (with a high $R^{2}$ ) appearing in all age classes, the mean crown profile showed as real scales following the CL in each thinning treatment. We used the model to compare the crown form of different thinning treatments in each age class. By examining the difference in the outline of the crown profile, we found that 
crown width increases with thinning intensity (Fig. 3).

Tree development is accompanied by changes in the external characteristics of the tree. The crown is the aboveground portion of the outline of trees and reflects growth periods, environmental conditions, and tree health (Hashimoto 1991, Baldwin et al. 2000, Filipiak 2005, Yen et al. 2006, Weiskittel et al. 2007). Tree growth involves complicated biological, chemical, and physiological mechanisms and is influenced by complex environmental factors (Kramer \& Kozlowski 1979, Hashimoto 1991, Baldwin et al. 2000, Yen et al. 2013). In general, using crowns to determine tree growth and its relationship with growth stages and environmental conditions is simple; therefore, crown characteristics, such as the CFPs and the CPE, are widely used to predict and explain growth phenomena resulting from environmental conditions (Yen et al. 2006, Chen et al. 2010). In a previous study, Yen et al. (2013) reported that thinning, particularly heavy thinning, positively affected biomass accumulation in different sections (leaves, branches, and boles) of Taiwan red cypress at tree level. Notably, this study also found that heavy thinning clearly improved crown outline and may cause biomass accumulation in different sections. This relationship confirms that crown condition is closely correlated with biomass accumulation, that is, heavier thinning creates larger spaces for tree developments, and heavier thinning treatments caused larger crown bodies and more biomass accumulation. On the other hand, Yen \& Wang (2013) also demonstrated that thinning effectively improved growth rate of stands, implying that thinning positively contributed to biomass accumulation and carbon sequestration at stand level.

However, the present study used the mean DBH of stands as a criterion to select representative trees in order to examine thinning effects at different tree age and crown characteristics. Since our knowledge on thinning effects on crown characteristics of differently sized trees is still limited, trees of different DBH classes are suggested to be sampled within stands in further studies to obtain more detailed information. Nevertheless, the CFP and CPE provided a quantifying method to interpret crown changes resulting from thinning for Taiwan red cypress plantations. Our study further found that more CFPs were influenced by thinning intensity in 27-year-old stands, implying that the CFPs were more suitable for describing crown changes in younger trees after thinning.

\section{Conclusions}

Taiwan red cypress is an economically crucial cypress conifer that grows in broad areas of plantation forest in Taiwan. However, only few studies have examined the relationship between crown characteristics and thinning, particularly in the long run. This study evaluated the crown form of Taiwan red cypress of three growth stages that received thinning treatments of differing intensity 20 years before. The results indicate that CFPs and the CPE are powerful tools for analyzing growth stages and thinning responses. However, CFPs exhibited little difference after thinning in different age classes. Our study further found that more CFPs were influenced by thinning intensity in 27-year-old trees, implying that the CFPs were more suitable for describing crown changes in younger trees after thinning. This result confirms that thinning intensity influences the crown properties of Taiwan red cypress varying with tree age classes, and provides useful information for forest management. Overall, the CFP and $\mathrm{CPE}$ provided a quantifying method to interpret crown changes resulting from thinning for Taiwan red cypress plantations.

\section{References}

Baldwin Jr V.C., Peterson K.D., Clark III A., Ferguson R.B. Strub M.R., Bower D.R., 2000. The effects of 
spacing and thinning on stand and tree characteristics of 38-year-old Loblolly Pine. Forest Ecology and Management 137: 91-102. DOI: 10.1016/S03781127(99)00340-0.

Baldwin Jr.V.C., Peterson K.D., 1997. Predicting the crown shape of loblolly pine tree. Canadian Journal of Forest Research 27: 102-107. DOI: 10.1139/x96-100.

Brix H., 1981. Effects of thinning and nitrogen fertilization on branch and foliage production. Canadian Journal of Forest Research 11: 502-511. DOI: 10.1139/x81-069.

Cai S., Kang X., Zhang L., 2013. Allometric models for aboveground biomass of ten tree species in northeast China. Annals of Forest Research 56(1): 105-122.

Chen Y.T., Yen T.M., Li C.L., 2010. Crown characteristics and crown shape of Japanese cedar (Cryptomerica japonica D. Don) in an even-aged stand. Quarterly Journal of Chinese Forestry 43: 213-221. [In Chinese].

Filipiak M., 2005. Changes of Abies alba crown state and stand quality class in the Sudety Mountains. Dendrobiology 54: 11-17.

Ginn S.E., Seiler J.R., Cazell B.H., Kreh R.E., 1991. Physiological and growth responses of eight-year-old loblolly pine stands to thinning. Forest Science 37: 1030-1040.

Hashimoto R., 1991. Canopy development in young sugi (Cryptomeria japonica) stands in relation to changes with age in crown morphology and structure. Tree Physiology 8: 129-143. DOI: 10.1093/treephys/8.2.129.

Hwang K.K., 1977. Studies on the growth of planted forest of red cypress. Quarterly Journal of Chinese Forestry 10: 95-109. [In Chinese].

Kramer P.J., Kozlowski T.T., 1979. Physiology of wood plants. MiGraw Hill, New York.

Lee J.S., 1985. Studies on the thinning of Taiwan red cypress plantation. Technical bulletin of department of forestry, National Chung-Hsing university. [In Chinese].

Lee J.S., Yen T.M., 2000. Evaluation of forest potential productivity of Chamaecyparis formosensis plantations- a study on site index curve. Quarterly Journal of Forest Research 22: 51-60. [In Chinese].

Li L.E., Yen T.M., 2010. Thinning effects on stand and tree levels of Taiwan red cypress (Chamaecyparis formosensis Matsum.) 4 years after years after thinned. Quarterly Journal of Chinese Forestry 43: 249-260. [In Chinese].

Liu Y.C., Lu F.Y., Ou C.H., 1988. Trees of Taiwan. Monographic publication No.7 College of Agriculture, National Chung-shing University. Taichung, Taiwan. pp. 76-80. [In Chinese].

Mäkinen H., Isomäki A., 2004. Thinning intensity and long-term changes in increment and stem form of Norway spruce trees. Forest Ecology and Management 201: 295-309. DOI: 10.1016/j.foreco.2004.07.017.

Pinkard E.A. Neilsen W.A., 2003. Crown and stand characteristics of Eucalyptus nitens in response to initial spacing: implications for thinning. Forest Ecology and Management 172: 215-227. DOI: 10.1016/S03781127(01)00803-9.

Simard S.W., Blenner-Hassett T., Cameron I.R., 2004. Pre-commercial thinning effects on growth, yield and mortality in even-aged paper birch stands in British Columbia. Forest Ecology and Management 190: 163 178. DOI: 10.1016/j.foreco.2003.09.010.

Taiwan Central Weather Bureau, 2013. Web: http://www. cwb.gov.tw/eng/index.htm. Accessed: 11.2014.

Taiwan Forestry Bureau, 1995. The Third National Forest Resources and Land Use in Taiwan. Taiwan Forest Bureau, pp. 1-258. [In Chinese].

Wang J., Fan J., Fan X., Zhang C., Wu L., Gadow K. v., 2013. Crown and root biomass equations for the small trees of Pinus koraiensis under canopy. Dendrobiology 70: $13-25$.

Weiskittel A.R., Maguire D.A., Monserud R.A., 2007. Response of branch growth and mortality to silvicultural treatments in coastal Douglas-fir plantations: Implications for predicting tree growth. Forest Ecology and Management 251: 182-194. DOI: 10.1016/ j.foreco.2007.06.007.

Yen T.M., 1999. Comparisons of direct and in direct estimation methods for stand structure of Chamaecyparis formosensis plantations. Quarterly Journal of Chinese Forestry 32: 347-356, [In Chinese].

Yen T.M., 2002. Stand density management of Chamaecyparis formosensis plantations. Quarterly Journal of Chinese Forestry 35: 55-67, [In Chinese].

Yen T.M., Ai L.M., Li C.L., Lee J.S., Huang K.L., 2009. Aboveground carbon contents and storage of three major Taiwanese conifer species. Taiwan Journal of Forest Science 24: 91-102.

Yen T.M., 2015. Comparing aboveground structure and aboveground carbon storage of an age series of moso bamboo forests subjected to different management strategies. Journal of Forest Research 20:1-8. DOI: 10.1007/s10310-014-0455-0.

Yen T.M., Lee J.S., Li C.L., Chen Y.T., 2013. Aboveground biomass and vertical distribution of crown for Taiwan red cypress 20 years after thinning. Dendrobiology 70: 109-116. DOI: 10.12657/denbio.070.012.

Yen T.M., Liu C.C., Chang W.J. 2006. Crown characteristics of China-fir (Cunninghamia lanceolata) in low stand density. Quarterly Journal of Chinese Forestry 39: 303-314 [In Chinese].

Yen T.M., Wang C.T., 2013. Assessing carbon storage and carbon sequestration for natural forests, man-made forests, and bamboo forests in Taiwan. International Journal of Sustainable Development \& World Ecology 20(5): 455-460. DOI: 10.1080/13504509. 2013.811445.

Yu S., Chambers J.L., Tang Z., Barnett J.P., 2003. Crown characteristics of juvenile loblolly pine 6 years after application of thinning and fertilization. Forest Ecology and Management 180: 345-352. DOI: 10.1016/S03781127(02)00582-0. 